\title{
Microfractures in metal-ceramic and all-ceramic implant-supported fixed dental prostheses caused by superstructure fixation
}

\author{
Matthias KARL ${ }^{1}$, Friedrich GRAEF², Manfred WICHMANN¹ and Nina BECK ${ }^{1}$ \\ ${ }^{1}$ Department of Prosthodontics, University of Erlangen-Nuremberg, Glueckstrasse 11, 91054 Erlangen, Germany \\ ${ }^{2}$ Department of Mathematics, University of Erlangen-Nuremberg, Martensstrasse 3, 91058 Erlangen, Germany \\ Corresponding author, Matthias KARL; E-mail: Matthias.Karl@uk-erlangen.de
}

\begin{abstract}
The effect of ceramic veneering on the passivity of fit of cast metal and CAD/CAM-fabricated zirconia ceramic implant-supported three-unit cement-retained restorations was investigated, as well as the effect of misfit stress on the marginal integrity of ceramic veneers. Superstructures were fabricated using cast metal or by CAD/CAM milling of presintered or HIP zirconia ceramic ( $n=10)$. Before and after veneering, strain gages were used to measure in vitro the strain developed in all the restorations as a result of superstructure fixation. Fluorescent penetrant method was used to detect microcracks developed in ceramic veneers. Cast frameworks showed significantly higher strain values than CAD/CAM frameworks $(p=0.000)$. Veneering significantly increased strain development in all CAD/CAM frameworks $(p=0.000)$. Compared to zirconia ceramic restorations, significantly more microcracks were observed in cast restorations $(p=0.000)$ both before and after superstructure fixation.
\end{abstract}

Keywords: Fluorescent penetrant method, Microfracture, Passive fit, Zirconia ceramic, Ceramic veneer

\section{INTRODUCTION}

Nonpassive-fitting implant-supported fixed dental prostheses (FDPs) can lead to both technical and biological complications, such as abutment fracture, connecting screw breakage, and bone loss ${ }^{1}$. It has been pointed out that superstructures fabricated by conventional methods such as casting failed to achieve a passive $\mathrm{fit}^{2-4}$. When multi-unit fixed restorations were fabricated using the computer-aided design/computeraided manufacturing (CAD/CAM) technique, greater accuracy was achieved ${ }^{5-9}$. The attractiveness of CAD/ CAM fabrication procedures is further boosted with the use of high-strength ceramic materials such as zirconia ceramic $^{10)}$.

For both conventionally cast metal restorations and CAD/CAM-fabricated restorations made from zirconia ceramic, ceramic veneers would be bonded onto their frameworks. Ceramic veneering was reported to negatively affect the precision of fit of cast implantsupported $\mathrm{FDPs}^{11}$. For zirconia ceramic restorations, contradicting results were reported. Dittmer et al. ${ }^{12)}$ and Kohorst et $a l .{ }^{13)}$ showed that ceramic veneering negatively affected the marginal and internal fit of four-unit zirconia restorations. Balkaya et al. ${ }^{14)}$ found that only the porcelain firing cycle affected the marginal fit of all-ceramic single crowns, but not so with the glaze firing cycle. On the other hand, Vigolo and Fonzi ${ }^{15)}$ found that neither the porcelain firing cycle nor the glaze cycle affected the marginal fit of four-unit CAD/CAMfabricated zirconia restorations.

Fixation of ceramic-veneered superstructures that lack passive fit results in strain development. Strain induced by misfit causes microfractures in the ceramic veneer $^{11}$. For this reason, chipping/fracture of the veneer is one of the most common causes of veneer failure in zirconia-supported all-ceramic restorations ${ }^{16}$. In a 5 -year clinical study by Sailer et al. ${ }^{17)}$, chipping of the veneering ceramic was cited as the second most common reason for failure of zirconia frameworks for posterior fixed partial dentures. Fractographic analyses of clinically failed zirconia-based FDPs by Taskonak et al. ${ }^{18)}$ showed that primary fractures initiated from the veneer surfaces, whereas interfacial delamination in glass veneer/zirconia core bilayer structures controlled the secondary fracture initiation sites.

Numerous studies have reported on the incidence of veneer chipping in zirconia restorations. Kreissl et al. ${ }^{19}$ found that fracture of the veneering porcelain occurred in $5.7 \%$ of the implant-supported FDPs after an average observation period of 5 years. Kollar et al. ${ }^{20)}$ reported that tooth- or implant-supported zirconia crowns in the posterior region exhibited porcelain veneer chipping after a follow-up period of up to 30 months. Raigrodski et al. ${ }^{21)}$ also reported on minor chipping of veneering porcelain in zirconia-based posterior three-unit restorations after short-term service. As for Edelhoff et $a l .{ }^{22)}$, a low incidence of veneer chipping, but no framework fractures, was observed in zirconia fixed partial dentures after a mean clinical observation period of over 39 months.

The goal of this study was to investigate a possible correlation between the passivity of fit of implantsupported zirconia FDPs and the fracture or chipping of ceramic veneers. First, the effect of ceramic veneering on the passivity of fit of cast metal and CAD/CAMfabricated zirconia ceramic implant-supported restorations was quantified. The effect of misfit stress on the occurrence of microcracks in the ceramic veneer was subsequently examined using the fluorescent penetrant method $^{11,23,24)}$. 


\section{MATERIALS AND METHODS}

A patient situation with two implants in the lower left mandible (Standard Plus Implants, Straumann AG, Basel, Switzerland; $4.1 \mathrm{~mm}$ diameter, $10 \mathrm{~mm}$ bone sink depth) was transferred to an in vitro resin model (Acryline clear, anaxdent, Stuttgart, Germany) suitable for strain gage measurements (Fig. 1).

\section{Fabrication of FDP frameworks}

1. Fabrication of master casts

A total of 30 pick-up impressions were made from the in vitro resin model using the implant manufacturer's transfer copings, custom-made impression trays (Palatray XL, Heraeus Kulzer, Hanau, Germany), and polyether impression material (Impregum, 3M ESPE AG, Seefeld, Germany). Based on these impressions, 30 master casts with individual dies containing the respective implant analogs were poured in type IV stone (Fujirock, GC Corp., Tokyo, Japan). Abutments 5.5 mm in height for cement-retained restorations (synOcta abutment "cement retained", Straumann AG, Basel, Switzerland) were then attached to the implants on the in vitro model and on the master casts.

Both CAD/CAM-fabricated and cast FDP frameworks had an identical design: lower first premolar and first molar as retainers and a lower second premolar as pontic.

\section{Fabrication of FDP frameworks with $\mathrm{CAD} / \mathrm{CAM}$}

Twenty of the master casts were used for CAD/CAM fabrication of cement-retained FDP frameworks. Half of these master casts were used to fabricate frameworks milled from presintered zirconia ceramic (Zerion, Straumann CAD/CAM, Gräfelfing, Germany), and the other 10 master casts were used for milling from HIP zirconia ceramic (Denzir, Straumann CAD/CAM GmbH, Gräfelfing, Germany). The entire CAD/CAM process from scanning the master casts to fabricating the zirconia ceramic frameworks was undertaken by Straumann CAD/CAM (Gräfelfing, Germany) (Fig. 2a).

3. Fabrication of FDP frameworks by casting

Based on the CAD/CAM restorations, a silicone mold (Silaplast, Detax GmbH \& Co KG, Ettlingen, Germany) was made for the fabrication of 10 cast frameworks. Using a pattern resin (Pattern Resin LS, GC Germany, Bad Homburg, Germany) and the implant manufacturer's burn-out plastic copings for cement-retained restorations, patterns resembling the design of the CAD/CAM restorations were manufactured on the remaining 10 master casts. These patterns were subsequently invested and cast with a high noble alloy for porcelain-fused-tometal restorations (Jensen Expert, Jensen Industries Inc., North Haven, CT, USA) (Fig. 2a).

\section{Strain gage measurement setup}

Visual and tactile evaluations of all restorations ( $n=10$ per group) were performed on the in vitro resin model to ensure a clinically acceptable fit with no visible marginal gaps. In the case of an obvious misfit, the space between implant abutment and FDP retainer was visualized

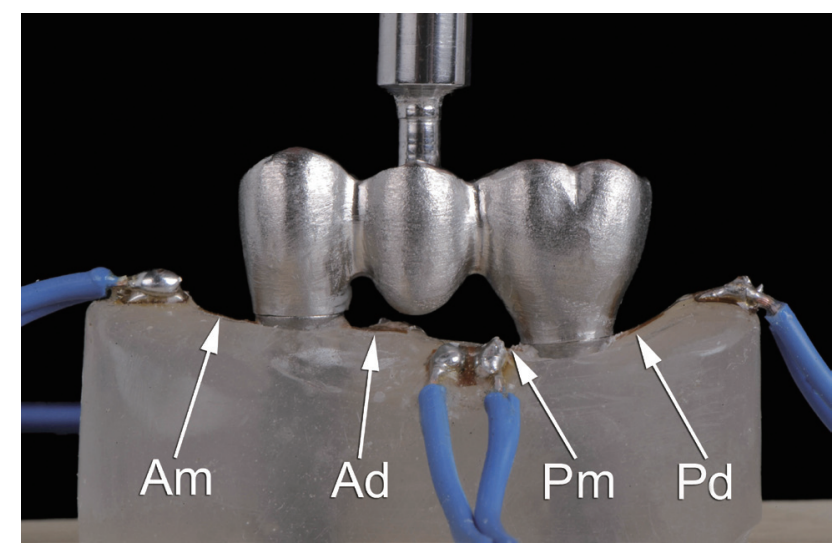

Fig. 1 In vitro model of an existing patient situation with two implants in a straight line configuration. A total of four strain gages attached mesially and distally adjacent to the implants captured the strains developed as a result of superstructure fixation. Here, a cast framework is cemented onto implant abutments with a force of $10 \mathrm{~N}$ exerted on the pontic through a universal testing machine.

using a light-body silicone (VOCO Fit Test C \& B, VOCO, Cuxhaven, Germany). Areas showing insufficient cement space were selectively ground until the cement space achieved a uniform thickness.

Four strain gages with a nominal resistance of 120 $\Omega$ each (LY11-0.6/120, Hottinger Baldwin Messtechnik, Darmstadt, Germany) were mounted on the in vitro model mesially and distally adjacent to the implants (Fig. 1). The strain gages were abbreviated as "SG" and named according to their positions: Am —-mesial SG at anterior implant; Ad — distal SG at anterior implant; Pm -mesial SG at posterior implant; Pd —distal SG at posterior implant $t^{4,11)}$. The strains developed around the implants were recorded using a measurement amplifier (Spider 8, Hottinger Baldwin Messtechnik, Darmstadt, Germany) and an analysis software (BEAM for Spider 8, AMS Gesellschaft für Angewandte Mess-und Systemtechnik, Flöha, Germany).

\section{Strain measurement before ceramic veneering}

A temporary cement (Temp Bond, Kerr Italia S.r.l., Scafati, Italy) was used for the fixation of all frameworks. It was mixed according to the manufacturer's recommendations. When the mixed cement was applied to the abutment cylinders, the SGs were set to zero. With the frameworks placed on the implant abutments, a force of $10 \mathrm{~N}$ was exerted on the pontic for $6 \mathrm{~min}$ using a universal testing machine (Inspekt mini $3 \mathrm{kN}$, Hegewald \& Peschke, Nossen, Germany). The load was removed, and the cement was allowed to set for a further $1 \mathrm{~min}$. After a total of $7 \mathrm{~min}$, the strain values before ceramic veneering at all strain gage positions of each restoration were recorded. 

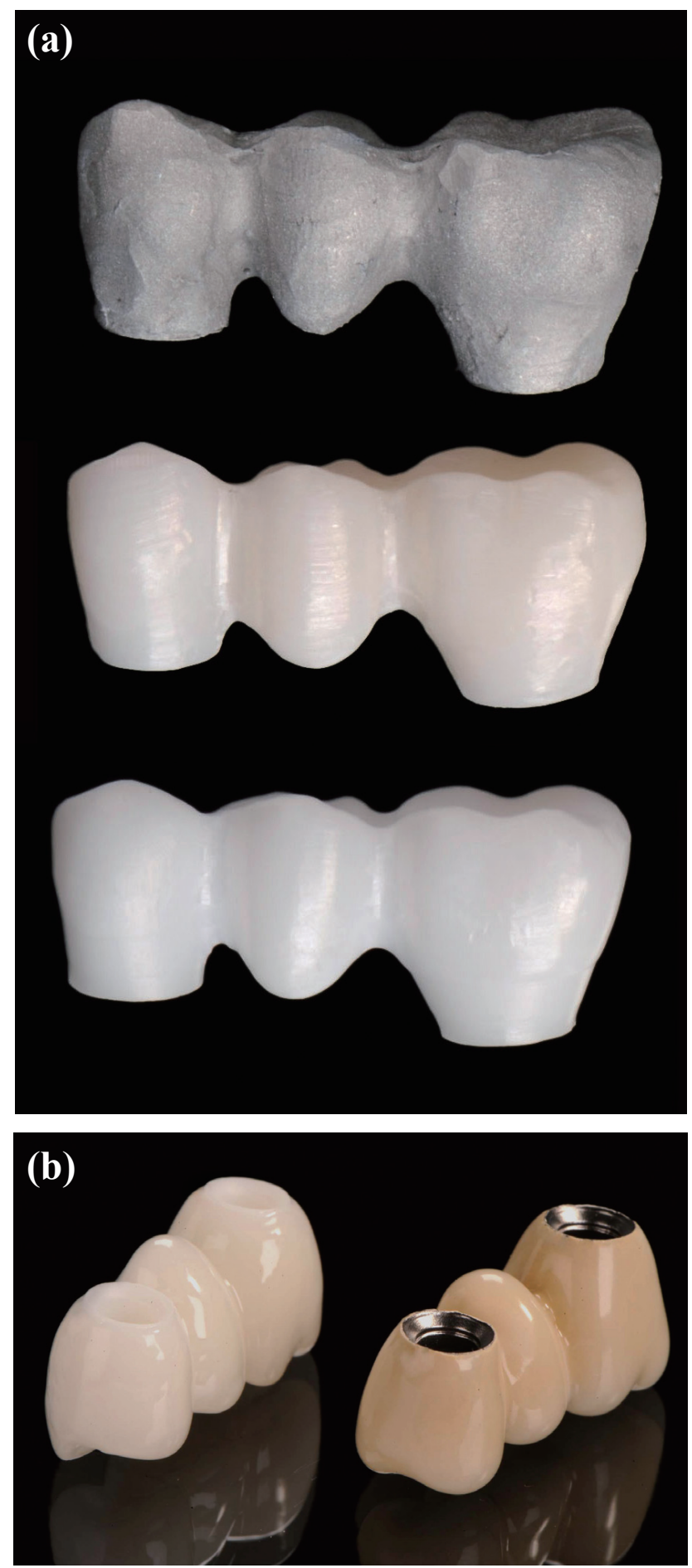

Fig. 2 a) FDP frameworks fabricated to fit the in vitro model. From top to bottom: conventionally cast FDP (high noble alloy); CAD/CAM FDP milled from HIP zirconia ceramic (Denzir); CAD/CAM FDP milled from presintered zirconia ceramic (Zerion).

b) $\mathrm{CAD} / \mathrm{CAM}$ frameworks (Denzir and Zerion) were ceramic-veneered by overpressing (left) and cast frameworks by layering (right).

\section{Ceramic veneering}

All frameworks were carefully retrieved from the implant abutments using a crown and bridge remover (Safe Remover, Anthogyr, Sallanches, France). The retainers were manually cleaned of cement remnants and then immersed in ethanol before veneering.

To standardize the veneering thickness of all restorations, one CAD/CAM-fabricated framework was veneered with overpressed ceramic (Cercon ceram press, DeguDent, Hanau, Germany) and used for obtaining a silicon mold (Silaplast, Detax GmbH \& Co KG, Ettlingen, Germany) prior to veneering the remaining CAD/CAM frameworks (Zerion and Denzir). For cast frameworks, they were veneered with the layering technique in strict adherence to the manufacturer's guidelines (Wegold Evolution, Wegold Edelmetalle AG, Wendelstein, Germany) (Fig. 2b). The firing protocol applied comprised one oxide bake $\left(820^{\circ} \mathrm{C}\right)$, opaque bake I and II $\left(820^{\circ} \mathrm{C}\right)$, dentin bake I and II $\left(770^{\circ} \mathrm{C}\right)$, and one polishing bake $\left(760^{\circ} \mathrm{C}\right)$. After firing, no additional treatments were applied to compensate for porcelain shrinkage.

1. Microfracture evaluation before superstructure fixation

After ceramic veneering, all frameworks were cleaned using isopropanol (MET-L-CHEK Spezialreiniger NPU, Helling, Heidgraben, Germany) and then immersed in a bath of fluorescent penetrant (MET-L-CHEK FP 97A(M), Helling GmbH, Heidgraben, Germany) for $24 \mathrm{~h}$. After drying under ambient conditions, the ceramic-veneered frameworks were inspected under a fluorescent lamp (HBO 100, Zeiss, Oberkochen, Germany) and a microscope (20× magnification; Axio Imager A.1, Zeiss GmbH, Oberkochen, Germany). All visible microcracks (Fig. 3) detected on both FDP retainers of each veneered framework were recorded using a digital camera (AxioCam MRc5, Zeiss, Oberkochen, Germany) mounted on the microscope and an image acquisition software (Imaging Software AxioVision 4.6.3, Zeiss, Oberkochen, Germany) ${ }^{11,23,24)}$.

2. Strain measurement and microfracture evaluation after superstructure fixation

After cementing all the veneered frameworks on the in vitro model, the strains developed around the implants were recorded using the four strain gages - as per the strain measurement done for superstructure fixation before ceramic veneering.

After the frameworks were removed from the in vitro model, they were again inspected for microcracks using the fluorescent penetrant method.

\section{Statistical analysis}

Statistical analysis on the absolute strain values was performed using multivariate analysis of variance with FDP type (Cast/Denzir/Zerion) and veneering status (veneered/not veneered) as fixed factors (SPSS version 19, IBM Inc., Somers, NY, USA).

Statistical analysis on the number of microcracks detected was performed with a generalized linear model using Poisson distribution. FDP type (Cast/Denzir/ Zerion) and fixation status (before cementation/after 


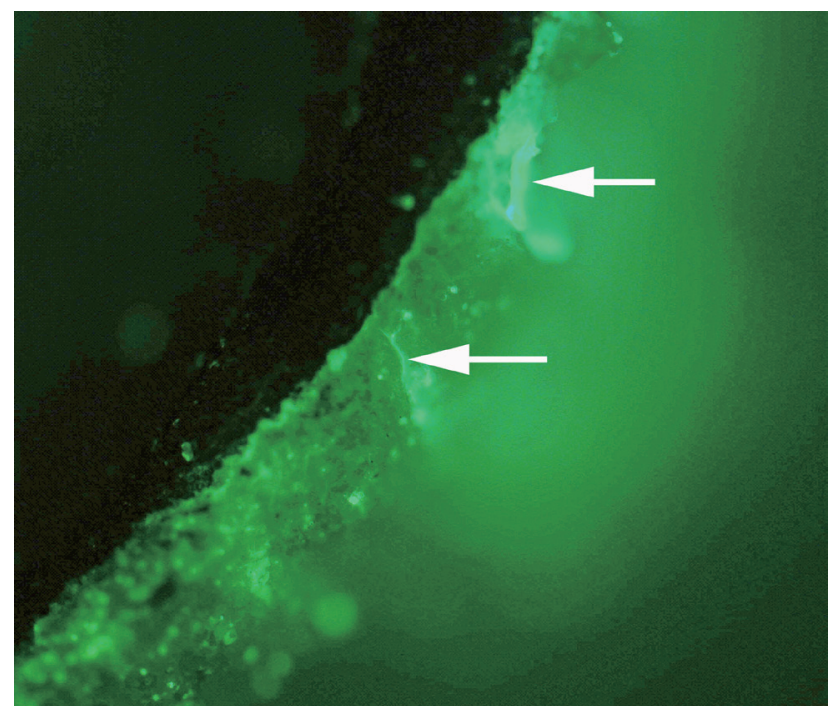

Fig. 3 Typical view of a FDP retainer under fluorescent light showing multiple radial cracks extending into the ceramic veneer.

cementation) were the fixed factors (R, The R Foundation for Statistical Computing, Vienna, Austria; www.R-project.org).

For all statistical comparisons, level of significance was set at $\alpha=0.05$.

\section{RESULTS}

\section{Strain development}

For all the unveneered FDP frameworks, their mean strain values at the four different strain gage positions ranged from $64.32 \mu \mathrm{m} / \mathrm{m}$ to $326.83 \mu \mathrm{m} / \mathrm{m}$. For the veneered restorations, the range was $69.19 \mu \mathrm{m} / \mathrm{m}-319.15$ $\mu \mathrm{m} / \mathrm{m}$ (Fig. 4). In general across all the four different strain gage positions, cast frameworks exhibited higher strain values than Denzir and Zerion frameworks $(p=0.000)$. In both unveneered and veneered conditions, cast frameworks also exhibited considerably higher values for the mean of standard deviations (which indicated the dispersion of developed strains) than Denzir and Zerion, which showed comparable values in both veneering conditions (Table 1). Nonetheless, all FDP frameworks (Cast/Denzir/Zerion) showed comparable mean strain values after ceramic veneering (Table 1).

Between the two types of CAD/CAM-fabricated FDP frameworks milled from HIP zirconia ceramic or presintered zirconia ceramic, no significant differences in strain development were detected $(p=0.165)$ (Table 2). In contrast, cast frameworks showed significantly higher strain values than Zerion $(p=0.000)$ and Denzir $(p=0.000)$ (Table 2). For both Denzir and Zerion frameworks, ceramic veneering resulted in a significant increase in strain development $(p=0.000)$. For cast frameworks, the effect of ceramic veneering on strain development was (a)

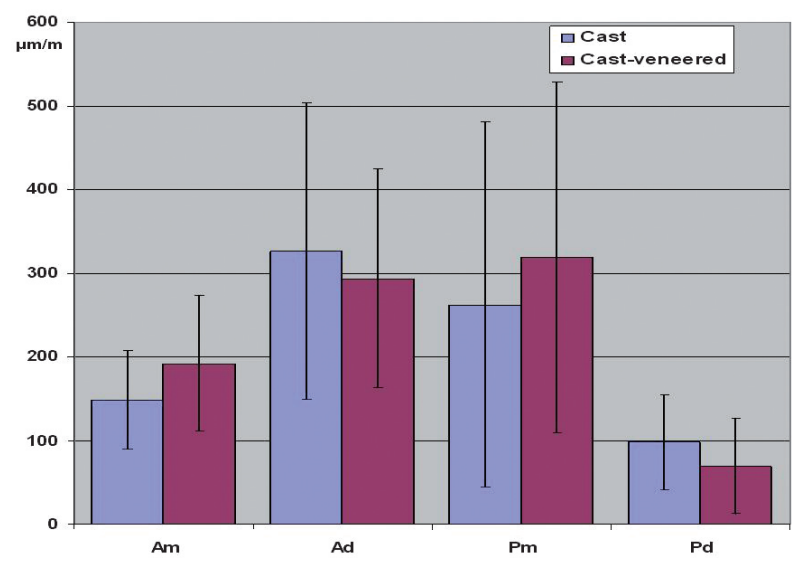

(b)

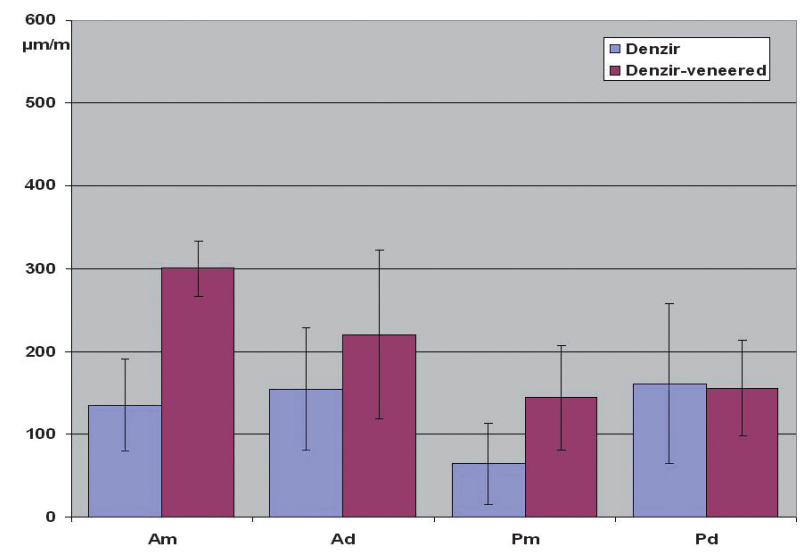

(c)

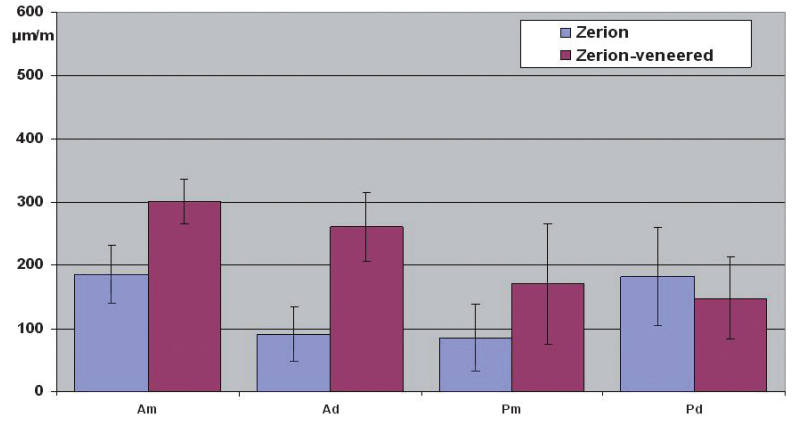

Fig. 4 Mean strain values at the four different strain gage positions for all types of FDP frameworks before and after ceramic veneering.

not significant (Table 2). After ceramic veneering, there were no significant differences in the strain values among the three FDP types.

\section{Microfracture evaluation}

After ceramic veneering, the mean numbers of microcracks detected in FDP retainers were as follows: 
Table 1 Mean strain values and means of standard deviations of all strain gage positions for all types of FDP frameworks

\begin{tabular}{llcc}
\hline FDP type & & Not veneered & Veneered \\
\hline Cast & Mean strain value & 208.920 & 218.634 \\
& Mean of standard deviations & 141.662 & 158.355 \\
\hdashline Denzir & Mean strain values & 128.700 & 205.098 \\
& Mean of standard deviations & 67.304 & 92.746 \\
Zerion & Mean strain values & 135.715 & 220.218 \\
& Mean of standard deviations & 71.570 & 91.399 \\
\hline
\end{tabular}

Table 2 Pairwise comparisons of FDP types based on strain development (MANOVA with Pillai's trace, level of significance $\alpha=0.05$ ); significant effects are given in bold

\begin{tabular}{|c|c|c|c|c|c|}
\hline & Value & $\mathrm{F}$ & Hypothesis df & Error df & $p$-value \\
\hline \multicolumn{6}{|l|}{ Zerion vs. Denzir } \\
\hline FDP type & 0.174 & 1.740 & 4.000 & 33.000 & 0.165 \\
\hline Veneering status & 0.801 & 33.306 & 4.000 & 33.000 & 0.000 \\
\hline FDP type : Veneering status & 0.256 & 2.843 & 4.000 & 33.000 & 0.039 \\
\hline \multicolumn{6}{|l|}{ Cast vs. Zerion } \\
\hline FDP type & 0.496 & 8.104 & 4.000 & 33.000 & 0.000 \\
\hline Veneering status & 0.517 & 8.842 & 4.000 & 33.000 & 0.000 \\
\hline FDP type : Veneering status & 0.258 & 2.873 & 4.000 & 33.000 & 0.038 \\
\hline \multicolumn{6}{|l|}{ Cast vs. Denzir } \\
\hline FDP type & 0.448 & 6.691 & 4.000 & 33.000 & 0.000 \\
\hline Veneering status & 0.651 & 15.379 & 4.000 & 33.000 & 0.000 \\
\hline FDP type : Veneering status & 0.277 & 3.162 & 4.000 & 33.000 & 0.026 \\
\hline
\end{tabular}

Table 3 Analysis of deviance on the effects of FDP type (Cast/Denzir/Zerion) and fixation status (before cementation/ after cementation) on the number of detectable microcracks; level of significance $\alpha=0.05$; significant effects are given in bold

\begin{tabular}{lccccc}
\hline & Df & Deviance & Residual Df & Residual Deviance & $p$-value \\
\hline Null & & & 59 & 152.975 & \\
FDP type & 2 & 87.267 & 57 & 65.707 & $\mathbf{0 . 0 0 0}$ \\
Fixation status & 1 & 14.150 & 56 & 51.558 & $\mathbf{0 . 0 0 0}$ \\
FDP type : Fixation status & 2 & 0.842 & 54 & 50.715 & 0.656 \\
\hline
\end{tabular}

0.1 in both Denzir and Zerion frameworks, and 1.6 in cast frameworks. After cementation, the mean numbers of detectable microcracks were as follows: 0.1 in Zerion, 0.5 in Denzir, and 4.2 in cast frameworks.

An analysis of deviance (Table 3) revealed a significant influence of the fixed factors, FDP type (Cast/ Denzir/Zerion) and fixation status (before cementation/ after cementation), on the number of detectable microcracks $(p=0.000)$. Based on coefficients for contrasts (Table 4), there were significant differences when comparing between Denzir and Cast groups $(p=0.000)$ and between Zerion and Cast groups $(p=0.000)$. In addition, there was a significant difference in the mean number of microcracks before and after cementation $(p=0.001)$.

In an analysis of deviance comparing Zerion and Denzir frameworks (Table 5), neither the fixed factors of FDP type $(p=0.148)$ and fixation status $(p=0.148)$ nor the interaction of both factors $(p=0.366)$ had a significant influence on the number of detectable microcracks.

Based on the mean strain development in all FDP types ( $p=0.548)$, no significant correlation between strain development and the number of microcracks could be established. However, a significant correlation between misfit strain dispersion and the number of microcracks was found ( $p=0.041)$. 
Table 4 Contrast coefficients based on number of detectable microcracks; level of significance $\alpha=0.05$; significant effects are given in bold

\begin{tabular}{lcccc}
\hline & Estimate & Standard error & $z$-value & $p$-value \\
\hline Denzir-Cast & -2.128 & 0.473 & -4.499 & $\mathbf{0 . 0 0 0}$ \\
Zerion-Cast & -3.738 & 1.012 & -3.694 & $\mathbf{0 . 0 0 0}$ \\
Before cementation-after cementation & -0.965 & 0.294 & -3.285 & $\mathbf{0 . 0 0 1}$ \\
\hline
\end{tabular}

Table 5 Analysis of deviance comparing Zerion and Denzir frameworks with fixed factors FDP type (Cast/Denzir/Zerion) and fixation status (before cementation/after cementation); level of significance $\alpha=0.05$; significant effects are given in bold

\begin{tabular}{|c|c|c|c|c|c|}
\hline & Df & Deviance & Residual Df & Residual Deviance & $p$-value \\
\hline Null & & & 39 & 28.524 & \\
\hline FDP type & 1 & 2.093 & 38 & 26.431 & 0.148 \\
\hline Fixation status & 1 & 2.093 & 37 & 24.338 & 0.148 \\
\hline FDP type : Fixation status & 1 & 0.818 & 36 & 23.520 & 0.366 \\
\hline
\end{tabular}

\section{DISCUSSION}

\section{Strain development}

Results of this study showed that cast frameworks exhibited greater strain values than CAD/CAMfabricated ones. This result agreed with previous studies which showed that the CAD/CAM fabrication method produced restorations with better accuracy of fit than conventional casting ${ }^{3,5-9)}$.

The choice of zirconia material in this study, i.e., HIP zirconia ceramic versus presintered zirconia ceramic, had no effect on strain development in the all-ceramic frameworks. This result contradicted a study conducted by Kohorst et al. ${ }^{25)}$ and a review published by Abduo et $a l .^{2)}$, which claimed that restorations made from fully sintered zirconia showed better fitting accuracy.

This study also showed that ceramic veneering of implant-supported superstructures resulted in an increase in strain development. This finding is supported by several studies on the effect of porcelain veneering on the accuracy of fit of zirconia restorations ${ }^{12-14,26)}$. An exception was found with a study by Vigolo and Fonzi ${ }^{15)}$, who reported that veneering did not affect the fitting accuracy of zirconia restorations.

The contradicting results by Kohorst et al. ${ }^{25)}$ as well as Vigolo and Fonzi ${ }^{15)}$ might be explained by the different study designs. In the current study, assessment was based on strain development, and hence fitting accuracy, using strain gage measurements ${ }^{11)}$. In the aforementioned studies $^{15,25)}$, assessment was based on marginal fit using gap measurements. As shown by Hegde et $a l .{ }^{4)}$, microgap measurements had no correlation with increasing misfit and that the presence or absence of a microgap was not necessarily indicative of passivity.

For cast frameworks, the effect of ceramic veneering was not as pronounced as that noted for CAD/CAMfabricated zirconia ceramic frameworks. In the present study, all FDP types showed comparable levels of misfit after veneering. It might be argued that the cast frameworks already reached maximum misfit in the as-cast condition, such that adding a ceramic veneer would not further aggravate the extent of misfit.

\section{Microfracture development}

After ceramic veneering, only two cracks were detected in both groups of zirconia ceramic frameworks. These microcracks could have resulted from residual stresses developed during the preparation of these all-ceramic implant superstructure ${ }^{27)}$. In contrast, a significantly greater number of microcracks was detected at the cervical margins of both FDP retainers in cast restorations.

After cementation, there was no significant increase in the number of microcracks in both groups of zirconiabased restorations — which did not differ significantly from each other. In contrast, the detectable microcracks in cast restorations significantly increased -an observation consistent with that in our previous experiment $^{11)}$. Extremely high strain values were recorded at the midstanding strain gage positions (Ad, $\mathrm{Pm}$ ) for cast restorations, which explained why there was a significant increase in the number of microcracks at the cervical margins of both FDP retainers. These high strain values were probably related to the hoop stresses which were developed when the superstructure was seated on conical abutments.

It is noteworthy that all veneered restorations exhibited comparable levels of total strain (averaged strain development at all strain gage positions). Based on the significant correlation between the number of microcracks and the dispersion of misfit strains $(p=0.041)$, it appeared that the distribution of strains was a greater deciding factor in microcrack formation than the total strain level of a restoration.

\section{Limitations of the study}

A few limitations need to be acknowledged regarding the present study. Besides the limited sample size and in 
vitro setting, one noteworthy limitation was the strain measurement method used. Strain gages could not be positioned directly at the implant shoulder. Therefore, strains were captured at an area away from the simulated bone-implant interface. Although the strain gages were positioned in the mesial-distal direction to capture the strains occurring in the direction of maximum principal stress, they failed to capture all the three-dimensional distortions which occurred. These distortions which are inherent in each implant-supported superstructure are inconsistent given their three-dimensional nature ${ }^{3)}$, and would thus result in positive and negative strain values at the sensors. In this study, absolute strain values were used for analysis, hence resulting in large standard deviations in all FDP groups.

To simulate current clinical practice, all zirconiabased frameworks were veneered with the overpressing technique and the cast restorations with the layering technique. Although the dental ceramic products chosen in this study were apt choices to represent the fully sintered and presintered zirconia types, the choice of zirconia-based dental ceramic for all-ceramic restorations could be a confounding variable itself. The cement type chosen might have also affected the experimental results. In most clinical implant cases, temporary cements are used for fixation of restorations, because definitive or adhesive resin cements would not allow access to the implant components at a later stage. Coupled with the need to remove all restorations from the in vitro model without damaging the model or the restoration, a temporary cement was used in this study.

The fluorescent penetrant method is currently considered as being sensitive enough for detecting surface microcracks in dental restorations. Although it has been shown that this technique is equally or better suited for microcrack detection than methods such as transillumination or scanning electron microscopy ${ }^{23,24)}$, it has not been clarified whether it could efficiently detect all cracks present. It also remains to be asked if the cracks identified by this method would ultimately lead to a clinical problem such as ceramic veneer chipping.

\section{CONCLUSION}

Within the limitations of this study, it was concluded that the addition of a ceramic veneer to a cast metal or milled zirconia ceramic FDP framework caused a decrease in passivity of fit. The veneering process itself might have already resulted in microcrack formation at the cervical margins of FDP retainers. Cementation of implant-supported restorations led to a general increase in the number of detectable microcracks, which was more pronounced in cast restorations than CAD/CAMfabricated zirconia-based restorations.

\section{REFERENCES}

1) Romero GG, Engelmeier R, Powers JM, Canterbury AA. Accuracy of three corrective techniques for implant bar fabrication. J Prosthet Dent 2000; 84: 602-607.
2) Abduo J, Lyons K, Swain M. Fit of zirconia fixed partial denture: a systematic review. J Oral Rehabil 2010; 37: 866-876.

3) Mitha T, Owen CP, Howes DG. The three-dimensional casting distortion of five implant-supported frameworks. Int J Prosthodont 2009; 22: 248-250.

4) Hegde R, Lemons JE, Broome JC, McCracken MS. Validation of strain gauges as a method of measuring precision of fit of implant bars. Implant Dent 2009; 18: 151-161.

5) Al-Fadda SA, Zarb GA, Finer Y. A comparison of the accuracy of fit of 2 methods for fabricating implant-prosthodontic frameworks. Int J Prosthodont 2007; 20: 125-131.

6) Tahmaseb A, van de Weijden JJ, Mercelis P, De Clerck R, Wismeijer D. Parameters of passive fit using a new technique to mill implant-supported superstructures: an in vitro study of a novel three-dimensional force measurement-misfit method. Int J Oral Maxillofac Implants 2010; 25: 247-257.

7) Kohorst P, Junghanns J, Dittmer MP, Borchers L, Stiesch M. Different CAD/CAM-processing routes for zirconia restorations: influence on fitting accuracy. Clin Oral Investig 2011; 15: 527-536.

8) Beuer F, Aggstaller H, Edelhoff D, Gernet W, Sorensen J. Marginal and internal fits of fixed dental prostheses zirconia retainers. Dent Mater 2009; 25: 94-102.

9) Karl M, Wichmann MG, Heckmann SM, Krafft T. Strain development in 3-unit implant-supported CAD/CAM restorations. Int J Oral Maxillofac Implants 2008; 23: 648-652.

10) Vagkopoulou T, Koutayas SO, Koidis P, Strub JR. Zirconia in dentistry: Part 1. Discovering the nature of an upcoming bioceramic. Eur J Esthet Dent 2009; 4: 130-151.

11) Karl M, Fischer H, Graef F, Wichmann MG, Taylor TD, Heckmann SM. Structural changes in ceramic veneered three-unit implant-supported restorations as a consequence of static and dynamic loading. Dent Mater 2008; 24: 464-470.

12) Dittmer MP, Borchers L, Stiesch M, Kohorst P. Stresses and distortions within zirconia-fixed dental prostheses due to the veneering process. Acta Biomater 2009; 5: 3231-3239.

13) Kohorst P, Brinkmann H, Dittmer MP, Borchers L, Stiesch $\mathrm{M}$. Influence of the veneering process on the marginal fit of zirconia fixed dental prostheses. J Oral Rehabil 2010; 37: 283-291.

14) Balkaya MC, Cinar A, Pamuk S. Influence of firing cycles on the margin distortion of 3 all-ceramic crown systems. J Prosthet Dent 2005; 93: 346-355.

15) Vigolo $P$, Fonzi F. An in vitro evaluation of fit of zirconiumoxide-based ceramic four-unit fixed partial dentures, generated with three different $\mathrm{CAD} / \mathrm{CAM}$ systems, before and after porcelain firing cycles and after glaze cycles. J Prosthodont 2008; 17: 621-626.

16) Coelho PG, Bonfante EA, Silva NR, Rekow ED, Thompson VP. Laboratory simulation of Y-TZP all-ceramic crown clinical failures. J Dent Res 2009; 88: 382-386.

17) Sailer I, Fehér A, Filser F, Gauckler LJ, Lüthy H, Hämmerle $\mathrm{CH}$. Five-year clinical results of zirconia frameworks for posterior fixed partial dentures. Int J Prosthodont 2007; 4: 383-388.

18) Taskonak B, Yan J, Mecholsky JJ Jr, Sertgöz A, Koçak A. Fractographic analyses of zirconia-based fixed partial dentures. Dent Mater 2008; 24: 1077-1082.

19) Kreissl ME, Gerds T, Muche R, Heydecke G, Strub JR. Technical complications of implant-supported fixed partial dentures in partially edentulous cases after an average observation period of 5 years. Clin Oral Implants Res 2007; 18: 720-726.

20) Kollar A, Huber S, Mericske E, Mericske-Stern R. Zirconia for teeth and implants: a case series. Int J Periodontics Restorative Dent 2008; 5: 479-487.

21) Raigrodski AJ, Chiche GJ, Potiket N, Hochstedler JL, 
Mohamed SE, Billiot S, Mercante DE. The efficacy of posterior three-unit zirconium-oxide-based ceramic fixed partial dental prostheses: a prospective clinical pilot study. J Prosthet Dent 2006; 96: 237-244.

22) Edelhoff D, Florian B, Florian W, Johnen C. HIP zirconia fixed partial dentures -clinical results after 3 years of clinical service. Quintessence Int 2008; 6: 459-471.

23) Fischer H, Karaca F, Marx, R. Detection of microscopic cracks in dental ceramic materials by fluorescent penetrant method. J Biomed Mater Res 2002; 61: 153-158.

24) Beck N, Graef F, Gerstbrein O, Karl M. Sensitivity of transillumination for detecting microcracks in feldspathic and zirconia ceramic materials. J Prosthet Dent 2010; 104:
301-305.

25) Kohorst P, Brinkmann H, Li J, Borchers L, Stiesch M. Marginal accuracy of four-unit zirconia fixed dental prostheses fabricated using different computer-aided design/ computer-aided manufacturing systems. Eur J Oral Sci 2009; 117: 319-325.

26) Oilo M, Gjerdet NR, Tvinnereim HM. The firing procedure influences properties of a zirconia core ceramic. Dent Mater 2008; 24: 471-475.

27) Swain MV. Unstable cracking (chipping) of veneering porcelain on all-ceramic dental crowns and fixed partial dentures. Acta Biomater 2009; 5: 1668-1677. 